\title{
Evaluation of Spectral Selectivity of High Temperature Multilayer Solar Absorber Thin Film
}

\author{
Atasi Dan ${ }^{1}$, Kamanio Chattopadhyay ${ }^{2,3}$, Harish C. Barshilia ${ }^{4}$, Bikramjit Basu $^{1,2}$ \\ ${ }^{1}$ Materials Research Centre, Indian Institute of Science \\ Bangalore 560 012, India \\ atasidan@iisc.ac.in \\ ${ }^{2}$ Interdisciplinary Centre for Energy Research, Indian Institute of Science \\ Bangalore 560 012, India \\ ${ }^{3}$ Materials Engineering, Indian Institute of Science \\ Bangalore 560 012, India \\ ${ }^{4}$ Nanomaterials Research Laboratory, Surface Engineering Division, CSIR-National Aerospace Laboratories \\ Bangalore 560 017, India
}

\section{Extended Abstract}

One of the important goals for modern science and technology is the efficient utilization of solar energy. Of the systems developed for harvesting solar energy, photovoltaics (PV: conversion of electricity from solar energy) remains widely focused field in India and worldwide. However, the solar thermal systems which introduces conversion of thermal energy from solar irradiation, should stimulate the quest for in-depth investigations with their variety of unexplored and interesting properties.

Spectrally selective absorber thin film is one of the most important components of solar thermal systems. Our group is working under the framework of 'Solar Energy Research Institute for India and the United States (SERIIUS)' to develop such absorber thin films which should possess maximum solar absorptance $(\alpha>0.95)$ and minimum thermal emittance $(\varepsilon<$ $0.05)$ with excellent thermal stability. The performance of the absorber is usually being evaluated by a metric, called "Selectivity $(\alpha / \varepsilon)$ ", which is the ratio of absorptance and emittance. Higher the selectivity, more promising the material will be for solar thermal applications. In addition, the absorber should have long term thermal stability at high operating temperature $\left(>400{ }^{\circ} \mathrm{C}\right)$, thermal shock resistance, excellent angular absorptance over a wide range of incidence angles, remarkable harness, scratch resistance, and stability in humid environment.

In this context, our overall objective was to fabricate a novel absorber thin film and to investigate the quality, effectiveness and lifetime of the absorber in order to promote its widespread use in photothermal systems. The present work will highlight our consistent attempts to prepare W/WAlN/WAlON/ $\mathrm{Al}_{2} \mathrm{O}_{3}$-based solar selective absorber coating on stainless steel (SS) substrate using magnetron sputtering. A very high absorptance of 0.958 in the solar spectrum and low thermal emittance of 0.08 in the infrared region have been achieved by varying the target power, deposition time and reactive gas flow rates. Not only that, the parameterization of deposition condition introduces a graded refractive index profile from substrate to surface, where $\mathrm{W}$ is the infrared reflector, WAIN serves as main absorbing layer, $\mathrm{WAlON}$ and $\mathrm{Al}_{2} \mathrm{O}_{3}$ act as semitransparent and anti-reflecting layer, respectively. The thin film has a thickness of $\sim 270 \mathrm{~nm}$ with individual layer thickness of $125,40,40$, and $23 \mathrm{~nm}$ for $\mathrm{W}$, WAIN, WAlON, $\mathrm{Al}_{2} \mathrm{O}_{3}$, respectively. The selectivity of thin film is retained at $95 \%$ humidity and $37^{\circ} \mathrm{C}$ for $400 \mathrm{~h}$. The coating can withstand a load of $4.5 \mathrm{~N}$ which enables the thin film to be classified as scratch resistant and adherent to the substrate. Most importantly, the absorber exhibits long term thermal stability up to $500{ }^{\circ} \mathrm{C}$ in air with superior photothermal conversion efficiency. The coating also showed thermal shock resistance at $400{ }^{\circ} \mathrm{C}$ while the sample was removed from the furnace and subsequently allowed for cooling down to room temperature for 100 cycles.

In summary, the newly developed W/WAlN/WAlON/ $/ \mathrm{Al}_{2} \mathrm{O}_{3}$ thin film with high solar selectivity, long term thermal stability, excellent mechanical properties and environmental stability can be a promising candidate for photothermal applications. 


\section{References}

[1] A. Dan, H. C. Barshilia, K. Chattopadhyay, B. Basu, "Solar energy absorption mediated by surface plasma polaritons in spectrally selective dielectric-metal-dielectric coatings: A critical review," Renewable and Sustainable Energy Reviews, vol. 79, pp. 1050-77, 2017.

[2] N. Selvakuma, H. C. Barshilia, "Review of physical vapor deposited (PVD) spectrally selective coatings for mid-and high-temperature solar thermal applications," Solar Energy Materials and Solar Cells, vol. 98, pp. 1-23, 2012.

[3] A. Dan, A. Biswas, P. Sarkar, S. Kashyap, K. Chattopadhyay, H. C. Barshilia, B. Basu, "Enhancing spectrally selective response of W/WAlN/WAlON/Al $\mathrm{O}_{2} \mathrm{O}_{3}$-based nanostructured multilayer absorber coating through graded optical constants," Solar Energy Materials and Solar Cells, vol. 176, pp. 157-66, 2018.

[4] A. Dan, J. Jyothi, K. Chattopadhyay, H. C. Barshilia, B. Basu, "Spectrally selective absorber coating of WAlN/WAlON/Al $\mathrm{O}_{3}$ for solar thermal applications," Solar Energy Materials and Solar Cells, vol. 157, pp. 716-26, 2016. 